REFERENCES AND/OR ACKNOWLEDGEMENTS

No conflict of interest.

\section{SPD-002 IMPROVEMENT IN AN ANTIMICROBIAL STEWARDSHIP PROGRAMME AFTER IMPLEMENTING A SCREENING ALERT SYSTEM}

${ }^{1}$ E Tevar ${ }^{*},{ }^{2}$ MJ Castillo Méndez, ${ }^{1}$ A Ferrer Machín, ${ }^{3}$ ML Padilla Salazar, ${ }^{3}$ L Abella Vázquez, ${ }^{4} \mathrm{~J}$ Ode Febles, ${ }^{1} \mathrm{~K}$ Álvarez Tosco, ${ }^{3} \mathrm{M}$ Hayek Peraza, ${ }^{1} \mathrm{MA}$ Ocaña Gómez, ${ }^{1} \mathrm{~J}$ Merino Alonso. ${ }^{1}$ Hospital Nuestra Señora De La Candelaria, Pharmacy Service, Santa Cruz De Tenerife, Spain; ${ }^{2}$ Hospital Nuestra Señora De La Candelaria, Computer Department, Santa Cruz De Tenerife, Spain; ${ }^{3}$ Hospital Nuestra Señora De La Candelaria, Internal Medicine, Santa Cruz De Tenerife, Spain; ${ }^{4}$ Hospital Nuestra Señora De La Candelaria, Microbiology Service, Santa Cruz De Tenerife, Spain

10.1136/ejhpharm-2020-eahpconf.21

Background and importance The implementation of an antimicrobial stewardship programme (AMSP) is very important but it has to be accompanied by personnel resources. It is therefore necessary to effectively use the time spent in the AMSP reviewing only those treatments that can be improved.

Aim and objectives To implement a screening alert system (SAS) that shows only those antibiotic treatments that could be improved by meeting predefined conditions and to evaluate the SAS.

Material and methods This was a quasi-experimental study. Using the information available in the electronic health record (EHR) and in the pharmacy and microbiology applications, we developed a computer tool that analysed hundreds of situations under pre-established conditions. For one month, before each AMSP team meeting, we recorded the total number of patients and prescribed antibiotics in the hospital compared with the number of treatments and patients that our system proposed to review.

The main variable of our study was number of patients to check before and after the tool. Secondary variables included number of antibiotics to review.

For the statistical analysis, the paired t test was used to determine if there were differences in the mean number of patients reviewed before and after using the SAS.

The analyses were performed using SPSS/PC statistical programme (V.24.0 for Windows, SPSS Inc, Chicago, Illinois, USA).

Results Seven services were included in the study: vascular surgery, cardiology, general surgery, geriatrics, internal medicine, neurology and traumatology. The number of antibiotics to review without the SAS in each AMSP team meeting was 21 (7-22) compared with 7 (3-9) when we used the SAS. Mean differences were found for patients to theoretically check before using the SAS (14 \pm 7 patients) compared with those who were actually checked after using the tool $(5 \pm 3$ patients) (mean difference 9 (95\% CI 5 to 12 patients); $\mathrm{p}=0.000124)$.

Conclusion and relevance This software allows the collection of information contained in different systems and displays only the relevant one in an organised view for the user. Limited personnel resources make the development of screening systems essential to optimise time and to prioritise which treatments need to be reviewed.

\section{REFERENCES AND/OR ACKNOWLEDGEMENTS}

1. Rodríguez-Baños J, et al. Programs for optimizing the use of antibiotics (PROA) in Spanish hospitals: GEIH-SEIMC, SEFH and SEMPSPH consensus document. Farm Hosp 2012;36(1).
No conflict of interest.

\section{SPD-003 ECONOMIC IMPACT OF THE INTRODUCTION OF LAMIVUDINE PLUS DOLUTEGRAVIR BITHERAPY IN HIV NAIVE PATIENTS}

L Cantarelli*, J Gonzalez Garcia, B Del Rosario Garcia, J Ramos Rodriguez, F Gutierrez Nicolas, J Garcia Cairos, S Garcia Gil, GJ Nazco Casariego. Complejo Hospitalario Universitario De Canarias, Pharmacy, Santa Cruz De Tenerife, Spain

\subsection{6/ejhpharm-2020-eahpconf.22}

Background and importance Recently, the GEMINIS I and II studies have demonstrated how lamivudine (3TC) with dolutegravir (DTG) bitherapy in naive patients is as effective as conventional triple therapy after 48 weeks of follow-up. ${ }^{1}$

Aim and objectives To analyse the 5 year economic impact of bitherapy treatment of HIV naive patients from the perspective of hospital management in a third level hospital

Material and methods A mathematical model in Excel format was designed to estimate the difference in costs between DTG/3TC bitherapy and the conventional regimens described in the GESIDA guide ${ }^{2}$ for naive patients, with a 5 year perspective:

- Dolutegravir/abacavir/lamivudine (DTG/ABC/3TC)

- Dolutegravir+emtricitabine/tenofovir alafenamide (DTG + FTC/TAF)

- Raltegravir+emtricitabine/tenfovir alafenamide (RAL+FTC/ TAF)

The model was applied using an incidence of the disease of 8.6 new cases per 100000 inhabitants (epidemiological surveillance information system of the government of Spain). The budgetary impact on a reference hospital serving a reference population of 350000 was estimated. The unit cost of the drugs was obtained from the BOTplus database.

Results The cost per month of treatment for the different recommended regimens was: 1007.43€ for DTG+FTC/TAF, $1122.73 €$ for RAL+FTC/TAF, 863.00€ for DTG/ABC/3TC and $637.74 €$ for 3 TC+DTG bitherapy.

The introduction of bitherapy meant a saving compared with other alternatives:

- $485 €$ patient/year compared with RAL+FTC/TAF and 634 $366.92 €(43.2 \%)$ after 5 years of treatment.

- $370 €$ patient/year compared with DTG+FTC/TAF and 483 $946.92 €(36.7 \%)$ after 5 years of treatment.

- 225.26€ patient/year compared with DTG+ABC/3TC therapy and $294640.08 €(26.1 \%)$ after 5 years of treatment.

Conclusion and relevance HIV treatment continues to have a high budgetary impact. The introduction of bitherapy (3TC/ DTG) in naive patients would mean a reduction in the direct costs of treating this pathology, with a saving of up to $40 \%$ compared with conventional therapies.

\section{REFERENCES AND/OR ACKNOWLEDGEMENTS}

1. Cahn $\mathrm{P}$, et al. Dolutegravir plus lamivudine versus dolutegravir plus tenofovir disoproxil fumarate and emtricitabine in antiretroviral-naive adults with HIV-1 infection (GEMINI-1 and GEMINI-2): week 48 results from two multicentre, double-blind, randomised, non-inferiority, phase 3 trials. Lancet 2019;393(10167):143-155.

2. Gesida-seimc. 2018. available at: http://gesida-seimc.org/wp-content/uploads/ 2019/02/Guia_Tar_Gesida_Ene_2019.pdf

No conflict of interest. 